Louisiana State University

LSU Digital Commons

Faculty Publications

Department of Biological Sciences

$9-1-2012$

\title{
Resource-based habitat associations in a neotropical liana community
}

James W. Dalling

University of Illinois at Urbana-Champaign

Stefan A. Schnitzer

Smithsonian Tropical Research Institute

Claire Baldeck

University of Illinois at Urbana-Champaign

Kyle E. Harms

Smithsonian Tropical Research Institute

Robert John

Indian Institute of Science Education and Research Kolkata

See next page for additional authors

Follow this and additional works at: https://digitalcommons.Isu.edu/biosci_pubs

\section{Recommended Citation}

Dalling, J., Schnitzer, S., Baldeck, C., Harms, K., John, R., Mangan, S., Lobo, E., Yavitt, J., \& Hubbell, S.

(2012). Resource-based habitat associations in a neotropical liana community. Journal of Ecology, 100

(5), 1174-1182. https://doi.org/10.1111/j.1365-2745.2012.01989.x

This Article is brought to you for free and open access by the Department of Biological Sciences at LSU Digital Commons. It has been accepted for inclusion in Faculty Publications by an authorized administrator of LSU Digital Commons. For more information, please contact ir@lsu.edu. 


\section{Authors}

James W. Dalling, Stefan A. Schnitzer, Claire Baldeck, Kyle E. Harms, Robert John, Scott A. Mangan, Elena Lobo, Joseph B. Yavitt, and Stephen P. Hubbell 


\section{Marquette University \\ e-Publications@Marquette}

Biological Sciences Faculty Research and

Publications

Biological Sciences, Department of

$9-2012$

\section{Resource-based habitat associations in a neotropical liana community}

James W. Dalling

Smithsonian Tropical Research Institute

Stefan A. Schnitzer

Marquette University, stefan.schnitzer@marquette.edu

Claire Baldeck

University of Illinois

Kyle E. Harms

Smithsonian Tropical Research Institute

Robert John

Indian Institute of Science Education and Research

See next page for additional authors

Follow this and additional works at: https://epublications.marquette.edu/bio_fac

Part of the Biology Commons

\section{Recommended Citation}

Dalling, James W.; Schnitzer, Stefan A.; Baldeck, Claire; Harms, Kyle E.; John, Robert; Mangan, Scott A.; Lobo, Elena; Yavitt, Joseph B.; and Hubbell, Stephen P., "Resource-based habitat associations in a neotropical liana community" (2012). Biological Sciences Faculty Research and Publications. 699. https://epublications.marquette.edu/bio_fac/699 


\section{Authors}

James W. Dalling, Stefan A. Schnitzer, Claire Baldeck, Kyle E. Harms, Robert John, Scott A. Mangan, Elena Lobo, Joseph B. Yavitt, and Stephen P. Hubbell 
Marquette University

e-Publications@Marquette

\section{Biology Faculty Research and Publications/College of Arts and Sciences}

This paper is NOT THE PUBLISHED VERSION; but the author's final, peer-reviewed manuscript. The published version may be accessed by following the link in the citation below.

Journal of Ecology, Vol. 100, No. 5 (September, 2012): 1174-1182. DOI. This article is (C) Wiley and permission has been granted for this version to appear in e-Publications@Marquette. Wiley does not grant permission for this article to be further copied/distributed or hosted elsewhere without the express permission from Wiley.

\section{Resource-based habitat associations in a neotropical liana community}

James W. Dalling

Department of Plant Biology, University of Illinois, Urbana, IL Smithsonian Tropical Research Institute, Unit 0948, DPO AA

Stefan A. Schnitzer

Smithsonian Tropical Research Institute, Unit 0948, DPO AA

Department of Biological Sciences, University of Wisconsin, Milwaukee, WI

Claire Baldeck

Program in Ecology, Evolution and Conservation Biology, University of Illinois, Urbana, IL

Kyle E. Harms

Smithsonian Tropical Research Institute, Unit 0948, DPO AA

Department of Biological Sciences, Louisiana State University, Baton Rouge, LA

Robert John

Indian Institute of Science Education and Research - Kolkata, Mohanpur 741252, West Bengal, India

Scott A. Mangan

Department of Biological Sciences, University of Wisconsin, PO Box 413, Milwaukee, WI

Elena Lobo 
Program in Ecology, Evolution and Conservation Biology, University of Illinois, Urbana, IL

Joseph B. Yavitt

Department of Natural Resources, Cornell University, Ithaca, NY

Stephen P. Hubbell

Smithsonian Tropical Research Institute, Unit 0948, DPO AA

Department of Ecology and Evolutionary Biology, University of California Los Angeles, Los Angeles, CA

\section{Summary}

1. Lianas are a conspicuous element of many tropical forests, accounting for up to $40 \%$ of woody stem density and $20 \%$ of species richness in seasonal forests. However, lianas have seldom been surveyed at sufficiently large spatial scales to allow an assessment of the importance of habitat variables in structuring liana communities.

2. We compare the association patterns of 82 liana species and an equivalent sample of tree species on the 50 ha Forest Dynamics Project plot on Barro Colorado Island, Panama, with topographic habitat variables (high and low plateau, slope, swamp and streamside), and thirteen mapped soil chemical variables. In addition, we test for liana species associations with canopy disturbance using a canopy height map of the plot generated using light detection and ranging.

3. For all liana species combined, densities differed among topographic habitat types in the plot, with significantly higher densities on the seasonally drier lower plateau habitat (1044 individuals $\mathrm{ha}^{-1}$ ) than the moister slope habitat (729 individuals $\mathrm{ha}^{-1}$ ). Lianas were also significantly more abundant than expected in areas with low canopy height.

4. The proportion of liana species associated with one or more topographic habitat variables (44\%) was significantly lower than that for trees (66\%). Similarly, liana species were significantly less frequently associated with PC axes derived from soil chemical variables $(21 \%)$ than trees $(52 \%)$. The majority of liana species $(63 \%)$ were significantly associated with areas of the plot with low canopy height reflecting an affinity for treefall gaps.

5. Synthesis. The habitat associations detected here suggest that liana density is associated primarily with canopy disturbance, and to a lesser extent with topography and soil chemistry. Relative to trees, few liana species were associated with local variation in topography and soil chemistry, suggesting that nutrient availability exerts only weak effects on liana community composition compared to trees. Results from this study support the contention that increases in forest disturbance rates are a driver of recently observed increases in liana abundance and biomass in neotropical forests.

\section{Introduction}

Lianas are an important component of species richness and structural diversity in lowland tropical forests accounting for up to $20 \%$ of woody plant diversity and $40 \%$ of stem density (Putz 1984; Putz \& Mooney 1991; Schnitzer \& Bongers 2002, 2011). Nonetheless, assessments of liana community composition and structure remain rare, perhaps because of a lack of resources for field identification, and because standardized protocols for liana surveys have only recently been developed

(e.g. Parren et al. 2005; Gerwing et al. 2006; Schnitzer, DeWalt \& Chave 2006; Schnitzer, Rutishauser \& Aguilar 2008). In the absence of these data, it remains unclear whether lianas behave like trees with regard to the distribution of coexisting taxa, and in their responses to variation in resource availability.

For trees, recent analyses conducted in large ( $>10$ ha) census plots have revealed the importance of habitat variability in shaping the distribution patterns and trait composition of communities 
(Harms et al. 2001; Potts et al. 2004; Valencia et al. 2004; Engelbrecht et al.2007; John et al. 2007). These analyses have shown that tree species frequently have distributional biases with respect to topography (e.g. Valencia et al. 2004; Gunatilleke et al.2006), which suggest sensitivity to underlying variation in soil moisture or nutrient availability. For example, 52 of the 171 most common species of shrubs and trees that occur in the Barro Colorado Island (BCl) 50-ha forest dynamics plot in Panama show distributional biases with respect to the plot's swamp habitat and 44 species with respect to slopes (Harmset al. 2001). Similarly, 104 of 258 tree species in the $\mathrm{BCl}$ plot show non-random associations with either high or low concentrations of one or more soil chemical variables (John et al.2007).

As yet, only limited evidence is available to assess whether lianas are equally sensitive to topographic variation and soil nutrient availability. At the landscape scale, liana stem density has been shown to increase, albeit modestly, with soil fertility (Proctor et al. 1983; Putz \& Chai 1987; Gentry 1991; Laurance et al. 2001), and more strikingly at the regional scale with decreasing precipitation, and increasing seasonality of rainfall (Schnitzer 2005; DeWalt et al.2010). As liana species richness scales with stem density (Schnitzer \& Carson 2001, 2010), diversity might be expected to show similar patterns. In small scale plot surveys, liana species richness has been shown to vary between floodplain and upland habitat types in the western Amazon, with higher richness on the upland sites (Burnham 2002, 2004), and across a gradient of soil fertility and nutrient availability in northern Borneo, with higher richness on more fertile, less drought-prone sites (DeWalt et al. 2006). Individual liana species distributions have also been shown to be related to soil nutrient and light availability (Chettri et al. 2010; Malizia, Grau \& Lichstein 2010).

Alternatively, lianas may be relatively insensitive to soil and topography, at least at local scales, if their distributions are primarily determined by local disturbance history. To varying degrees, lianas have often been classified as early successional species (e.g. Putz 1984; Putz \& Chai 1987; Hegarty 1991; Campbell \& Newbery $\underline{1993}$ ), and are often noticeably more abundant in young secondary forest and at forest margins (e.g. DeWalt, Schnitzer \& Denslow 2000; Laurance et al. 2001; Arroyo-Rodríguez \& Toledo-Aceves 2009) and in treefall gaps (Putz 1984; Schnitzer, Dalling \& Carson 2000; Schnitzer \& Carson 2001, 2010). However, no study has tested whether resource availability or local disturbance provides a better explanation for liana distribution within a forest.

In this study, we use a complete census of the lianas ( $\geq 1 \mathrm{~cm}$ diameter) in the $\mathrm{BCl}$ 50-ha plot (S.A. Schnitzer, unpublished data) to compare liana densities across topographic habitat types, and to compare the frequency of liana vs. tree species associations with habitat type, and with soil chemical variables surveyed across the plot. In addition, we use a high-resolution map of forest canopy height determined using light detection and ranging (LiDAR) to test for liana species associations with low canopy heights related to gap disturbance.

Understanding the drivers of liana community assembly has become a priority given recent observations of increasing liana abundance in neotropical forests (e.g. Phillips et al. 2002; Foster, Townsend \& Zganjar 2008). In turn, high liana loads in forest canopies have been associated with reduced tree growth rates (Schnitzer \& Carson 2010), elevated tree mortality rates (Ingwell et al. 2010) and reduced above-ground biomass (van der Heijden \& Phillips 2009). Based on previous work at BCl showing that liana species richness is significantly higher in gaps than in the forest understorey (Schnitzer \& Carson 2001), we predict that liana species will be associated primarily with areas of low canopy height, rather than with habitats defined by topography or soil nutrients, previously shown to be important for tree species. If so, regional increases in liana abundance may reflect increasing disturbance rates in tropical forests, potentially resulting either from faster forest turnover rates or from elevated tree mortality rates (Condit, Hubbell \& Foster 1995; Phillips et al.2009). Alternatively, if observed regional variation in liana abundance reflects a competitive advantage for lianas in more seasonal environments (Schnitzer 2005), then we would predict that lianas would be most frequently associated with plateaus, the most seasonally moisture-limited topographic habitat types. 


\section{Materials and methods}

\section{Study Site and Species}

The study was carried out in seasonally moist tropical forest on ( $\mathrm{BCl})$, Panama $\left(9^{\circ} 10^{\prime} \mathrm{N}, 79^{\circ} 51^{\prime} \mathrm{W}\right)$. Rainfall on $\mathrm{BCl}$ averages $2600 \mathrm{~mm}$ year ${ }^{-1}$, with a pronounced dry season from January to April (Windsor 1990). The flora and vegetation of $\mathrm{BCl}$ have been described by Croat (1978) and by Foster \& Brokaw (1982). Investigations were carried out within the Forest Dynamics Project 50-ha plot, on the central plateau of BCl (Hubbell \& Foster 1983). The plot was established in 1982, and all free-standing trees $>1 \mathrm{~cm}$ diameter at breast height (d.b.h.) have been mapped and measured every 5 years since 1985. Soils at $\mathrm{BCl}$ are mostly well-weathered kaolinitic Oxisols. The 50-ha plot mostly overlies an andesite cap covering the centre of the island (Johnson \& Stallard 1989).

In 2007, we tagged, mapped, measured and identified all rooted lianas $\geq 1 \mathrm{~cm}$ diameter using the census methods described by Gerwing et al. (2006). For a complete description of the liana census, see Schnitzer, Rutishauser \& Aguilar (2008). We considered each liana that was rooted but not connected to another liana to be an apparent genet (Schnitzer, DeWalt \& Chave 2006). When a liana individual had multiple rooted stems $\geq 1$ $\mathrm{cm}$ in diameter, we considered the largest diameter stem to be the principal stem, and the smaller stems to be vegetatively produced ramets (S.A. Schnitzer, unpublished data). For each ramet and apparent genet, we measured the stem diameter $1.3 \mathrm{~m}$ from the rooting point and marked each plant with a uniquely numbered aluminium tag. We identified all lianas to species level in the field using a combination of stem, leaf and flower characteristics. We spatially mapped the rooting point of each liana using the existing $200005 \times 5$ m grid markers.

For our assessment of species-habitat associations described here, we report results for the liana data set consisting of 44971 apparent genets (henceforth 'individuals') of the 82 liana species with >65 individuals in the plot. This is the minimum abundance threshold used in a prior analysis of tree habitat associations within the $\mathrm{BCl}$ 50-ha forest plot (Harms et al.2001). Results obtained using all liana stems rather than all individuals were similar. For comparisons of habitat and soil associations between lianas and trees, we used a subset of 82 species from the $\mathrm{BCl}$ tree community. Trees were selected by taking the species with the population size in the plot that most closely matched the population size of each liana species. In aggregate, the tree community was represented by 44515 individuals. On average, differences in population sizes between the liana and matched tree taxa were $<4 \%$.

\section{Analysis of Habitat Associations}

Analysis of species distributions in relation to environmental factors requires accounting for the dispersion patterns of plants, which are generally more aggregated than random (Condit et al. 2000), and for the consequent lack of independence in the spatial location of conspecific individuals

(e.g. Plotkin et al. 2000; Harms et al. 2001). Here, we account for spatial autocorrelation in plant population distributions and habitat variables to test for associations of liana species with topographically defined habitat types, and in relation to environmental gradients defined by soil resource and light availability.

To determine whether liana species show associations with topographically defined habitats, we used the torustranslation test, which was previously used to describe the associations of trees and shrubs in the $\mathrm{BCl} 50$-ha plot (Harms et al. 2001). Briefly, each of $20 \times 20 \mathrm{~m}$ quadrats in the plot $(n=1250)$ was assigned to habitat types (Table 1; see also Fig. 1 in Harms et al. 2001) based on drainage (streams and swamp), slope and elevation (low plateau, slope and high plateau), and forest age (young forest). All but 66 quadrats were assigned to one of these six habitat types. The remaining quadrats with mixed habitats were excluded from this analysis. To test liana-habitat associations against a random expectation, the map of lianas remained stationary, while the plot habitat map was moved (i.e. translated) by $20 \mathrm{~m}$ increments in each of the cardinal directions about a two 
dimensional torus. Torus translations then provide 1249 habitat maps with which to compare the observed map. For the observed map, and each torus translation, relative stem densities for each species were calculated for each habitat. If the relative density of a liana species in a particular habitat was determined from the observed habitat map to be more extreme than $97.5 \%$ of the simulated relative density values for that species-habitat pairing, then it was considered to be either positively or negatively associated with the habitat

(Harms et al.2001).

Table 1. Habitat classification for the Barro Colorado Island (BCl) 50-ha forest dynamics plot. Individual densities are from the 2007 liana census

\begin{tabular}{|c|c|c|c|c|}
\hline Habitat & Total area (ha) & Number of individuals ha-1 & Canopy height $(\mathrm{m})$ & Area in gaps (\%) \\
\hline Old forest: low plateau & 24.80 & $1043.7^{*}$ & $24.6(8.1)$ & 3.3 \\
\hline Old forest: high plateau & 6.80 & 849.4 & $24.3(7.7)$ & 3.3 \\
\hline Old forest: slope & 11.36 & $728.7^{+}$ & $27.0(8.5)$ & 2.5 \\
\hline Old forest: swamp & 1.20 & 571.7 & $25.2(8.4)$ & 4.5 \\
\hline Old forest: streamside & 1.28 & 1044.5 & $22.9(9.0)$ & 10.4 \\
\hline Young forest & 1.92 & 1058.3 & $20.2(6.5)$ & 3.8 \\
\hline Mixed & 2.64 & 855.3 & $25.3(7.8)$ & 3.1 \\
\hline
\end{tabular}

Quadrats of $20 \times 20 \mathrm{~m}$ were classified according to slope $\left(<7^{\circ}\right.$ indicates a plateau) and elevation (low plateau sites are $<152 \mathrm{~m}$. a.s.l.). Mean canopy height $( \pm S D)$ and percentage in gaps $(<10 \mathrm{~m}$ canopy height $)$ were calculated from $5 \times 5$ m quadrat data.

*Significantly higher.

${ }^{\dagger}$ Significantly lower than expected liana density $\alpha=0.05$. 
(a) Habitat type and liana individuals
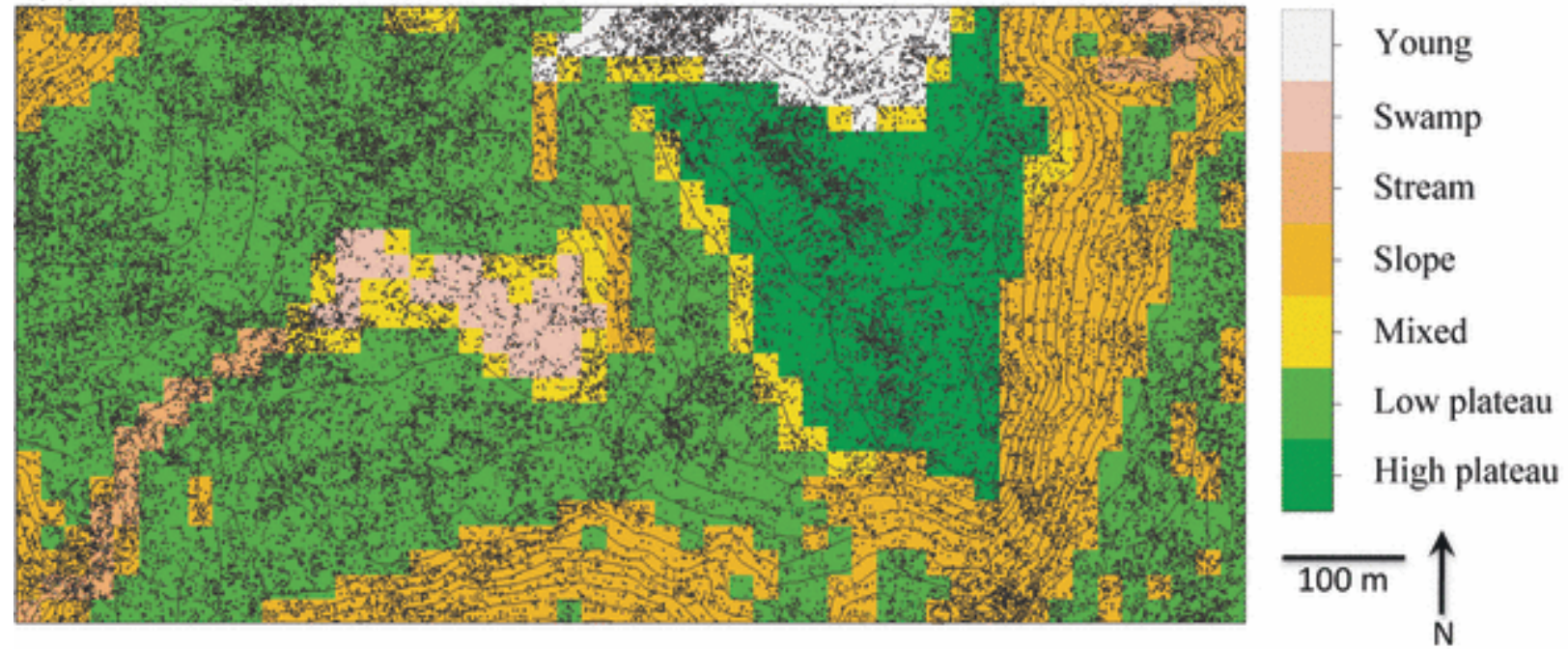

(b) Canopy height map

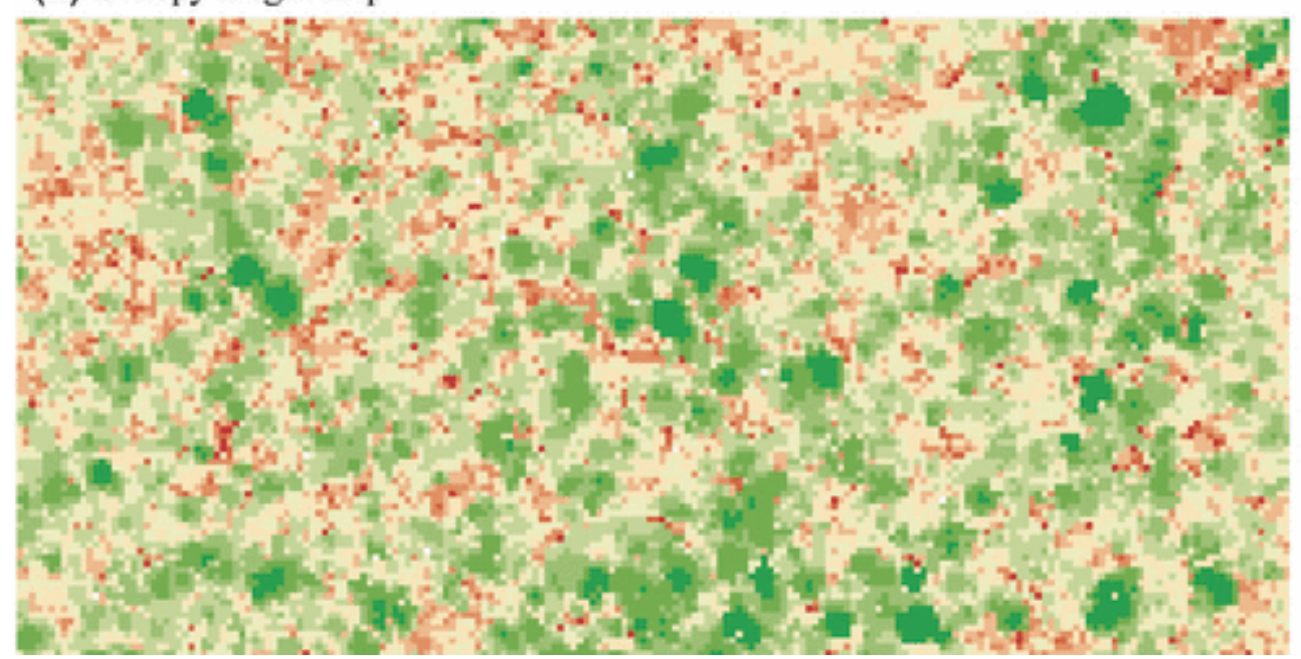

Canopy height $(\mathrm{m})$

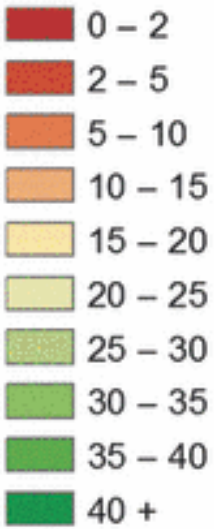

Figure 1

(a) The distribution of liana stems ( $\geq 1 \mathrm{~cm}$ diameter) in relation to habitat type classified for each $20 \times 20$ $\mathrm{m}$ quadrat in the Barro Colorado Island, 50-ha forest dynamics plot, Panama. The plot is $1000 \mathrm{~m}$ on the $x$-axis and $500 \mathrm{~m}$ on the $y$-axis. Black points indicate the location of liana individuals $>1 \mathrm{~cm}$ diameter. (b) The distribution of canopy heights across the plot measured using light detection and ranging and averaged for each $5 \times 5$ m quadrat.

\section{Analysis of Soil Resource Availability}

Soil analyses and mapping are described by John et al. (2007). Briefly, surface soils (0-10 cm depth) were sampled in the 50-ha plot using a regular grid of points every $50 \mathrm{~m}$, supplemented with additional paired samples at 2,8 or $20 \mathrm{~m}$ at alternate grid points. The additional samples were located at random compass directions from the grid and were used to capture variation in soil properties at finer spatial scales. In total, 300 samples were collected in the mid-wet season (June-August 2003). Cations ( $\mathrm{Al}, \mathrm{B}, \mathrm{Ca}, \mathrm{Cu}, \mathrm{Fe}, \mathrm{K}, \mathrm{Mg}, \mathrm{Mn}, \mathrm{Zn}$ ) and $\mathrm{P}$ were extracted in a Mehlich III solution and analysed using inductively coupled plasma spectroscopy. Nitrogen was extracted as $\mathrm{NH} 4+$ and $\mathrm{NO} 3-$ in $2 \mathrm{M} \mathrm{KCl}$ and analysed colorimetrically. $\mathrm{pH}$ was measured on a 1 : 3 mixture of fresh soil and distilled water. Additional measurements of $\mathrm{N}$ mineralization were taken following a 28-day in situincubation. Spatial predictions of soil nutrient availability were made for $10 \times 10$ m quadrats using ordinary kriging implemented using the R package 'GSTAT' (Pebesma 2004). 


\section{Analysis of Soil Resource Associations}

The distribution of every liana species was found to be significantly aggregated within the 50-ha plot (S.A. Schnitzer, unpublished data). Therefore, associations of individual liana species distributions (and of the entire liana community) with resource availability were assessed using the Poisson Cluster Model

(PCM; Plotkin et al. 2000). Under this procedure, the Ripley's K function (Ripley 1976) of each species was fit using the R package 'SPATSTAT' (Baddeley \& Turner 2005) and used to generate simulated distributions that preserve observed spatial aggregation patterns. The simulated distributions were then used to construct expectations for resource association patterns under the null hypothesis of no association. Further details on how the PCM is used to test for habitat associations are provided by John et al. (2007). For each combination of an observed species distribution and a resource map, we computed the mean value of the soil variable at all occurrences of the species. The observed mean values for each species and each resource map were then compared against the same indices computed for 1000 simulated species maps constructed using the PCM. The simulated means and standard deviations were used to generate the expectations for index values in the absence of resource associations (the dispersal assembly null model). Significant deviations of observed index values from the null expectation then indicate non-random effects related to resource supply. Statistical significance was assessed using a two-tailed test ( $\alpha=0.025$ for each tail) for species means.

To reduce the number of pairwise comparisons of soil resource maps with species distributions, we assessed the frequency of soil resource associations using the first three axes derived from principal component analysis of the thirteen soil variables (eigenvalues, nutrient loadings, variance explained and significance values for PC axes are provided in Table S1 in Supporting Information). As a further estimate of the frequency of Type 1 errors that may arise from spurious associations of species with soil variables, we used the approach of John et al. (2007). We compared the number of species-soil associations that were found when the distribution of the $\mathrm{BCl}$ liana community was compared to soil resource distributions generated using identical methods for another seasonally moist tropical forest, the Huai Kha Kheng (HKK) plot in Thailand. Subtracting the number of (spurious) associations found between HKK soils and $\mathrm{BCl}$ lianas then provides a more conservative estimate of the frequency of liana-soil associations. Although the absolute frequency of apparent soil-species associations is likely to be inflated by Type 1 error, the distribution of associations across soil variables may provide indications as to which variables impact plant performance. We therefore compared the frequency distribution of associations of lianas with that of the $\mathrm{BCl}$ tree community using the same methods (John et al. 2007).

\section{Analysis of Canopy Height Data}

Detailed georeferenced data on forest canopy height were obtained from an overflight of $\mathrm{BCl}$ conducted in August 2009 using an Optech ALTM Gemini LiDAR instrument (Optech International Inc., Kiln, MS, USA) flown at $460 \mathrm{~m}$ above the canopy with a first laser pulse return density of $6.5 \mathrm{~m}^{2}$ (BLOM Sistemas Geoespaciales SLU, unpublished quality control report). Difference in first and last laser returns, indicating the maximum canopy height, was averaged over each $5 \times 5 \mathrm{~m}$ quadrat within the plot to generate a canopy height map (Fig. 1). Canopy height on the $\mathrm{BCl}$ plot is normally distributed (mean $=26 \mathrm{~m}$, SD $=8 \mathrm{~m}$; maximum height = $50 \mathrm{~m})$. Low canopy heights indicative of canopy disturbance were extensively ground-truthed in the 2 months following LiDAR acquisition. At 109 of the $5 \times 5$ m grid intersection points with LiDAR returns indicating a canopy height of $<12 \mathrm{~m}$, canopy height was also measured from the ground using a laser rangefinder. Low-canopy sites always coincided with openings in the main canopy to at least $12 \mathrm{~m}$; the majority of sample points were associated with treefalls, but for some smaller areas, the opening was linked to a branch fall (E. Lobo, unpublished data).

Tests of liana species associations with the canopy height map were performed using the PCM as above. However, our primary interest was in determining whether lianas occur in canopy gaps; therefore, we use a onetailed test to assess significance of liana associations with low canopy height. To estimate the frequency of 
chance associations of lianas with canopy gaps (the type I error rate), we also compared species distributions in the 50-ha plot with canopy height maps generated for three 50-ha forest patches neighbouring the plot.

\section{Results}

\section{Associations of Lianas with Habitat Variables}

For all species combined, we found that lianas showed significant associations with the two most spatially extensive habitat types: lianas were significantly less common than expected on slopes, and more common than expected on the lower plateau (Table 1). Examining species-specific patterns, we found that 36 (44\%) of 82 species had a significantly higher or lower than expected density on one or more habitat types (Table S2). The highest frequency of association for individual liana species was found with the slope habitat (14 positive; four negative), followed by the swamp (eight positive; five negative), and upper plateau (five positive; three negative). Few species were associated with the low plateau, which encompasses almost half the plot, despite the high liana density in this habitat type, or with the rarer stream and young forest habitat types.

When compared with the matched sample of tree species (Fig. 2; Harms et al. 2001), we found that overall, the distribution of significant associations across habitat variables was not significantly different for trees and lianas (Chi-square test, $\chi^{2}=1.2, P>0.05$ ); however, the overall frequency of species showing significant associations with habitat variables was higher for trees $(66 \%)$ than lianas $\left(44 \% ; \chi^{2}=4.9, P<0.05\right)$.

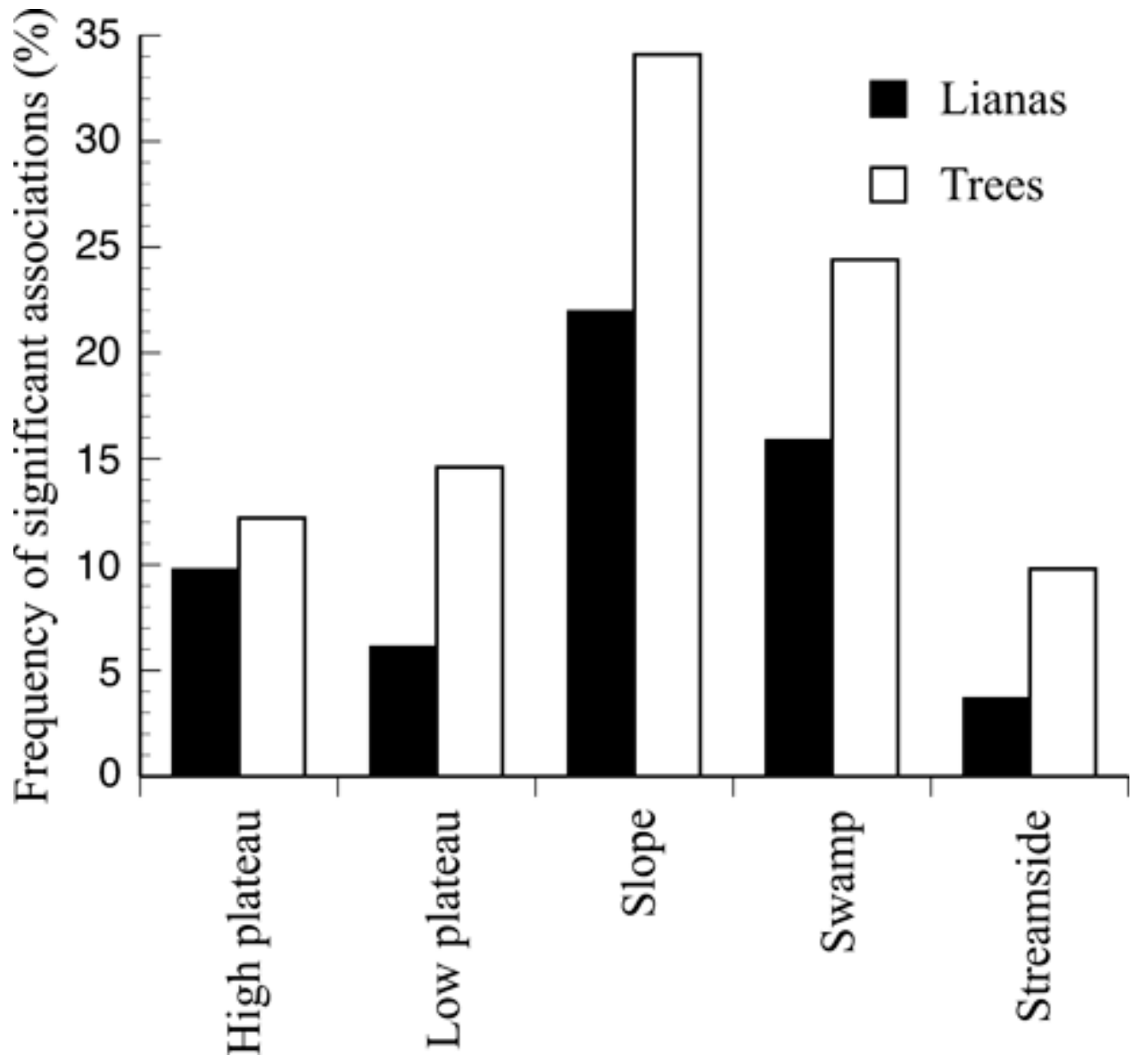

Figure 2

Percentage frequency of significant associations between either liana species (filled bars) or tree species (open bars) with topographically defined habitat types. Analysis is restricted to the 82 liana species with >65 individuals and a sample of 82 tree species with similar population sizes (tree data from Harms et al. 2001). 


\section{Associations of Lianas with Soil Variables}

Seventeen liana species (21\%) were significantly associated with sites with high or low axis scores for soil chemical variables, with a similar frequency of positive and negative associations (Table S3). Overall, the frequency of association of liana species with the PC axes was significantly lower than that of the matched sample of tree species $\left(52 \%, \chi^{2}=16.4, P<0.001\right)$. To further assess what fraction of these associations might arise by chance, we also compared liana distributions to the three PC axes generated from soil maps of a different 50-ha plot (HKK). This comparison yielded a null expectation of significant associations of 12 liana species (15\%) with high or low PC axis scores. Thus, subtracting an estimate of the frequency of spurious associations leaves an estimate of $c .6 \%$ of liana species associated with unexpectedly high or low levels of soil variables. In comparison, the sample of tree species resulted in 28 associations (34\%) with the HKK data, leaving c. $18 \%$ of tree species similarly associated.

Finally, we compared the frequency of association of lianas with soil chemical variables in the $\mathrm{BCl} 50$-ha plot with those for the matched tree sample. The frequency of association across different soil chemical variables was not correlated between trees and lianas (Fig. 3; Spearman $r=0.08, P=0.78$ ). Furthermore, nearly twice as many tree as liana species were positively or negatively associated with soil variables (Wilcoxon test, $P$ $<0.001)$.

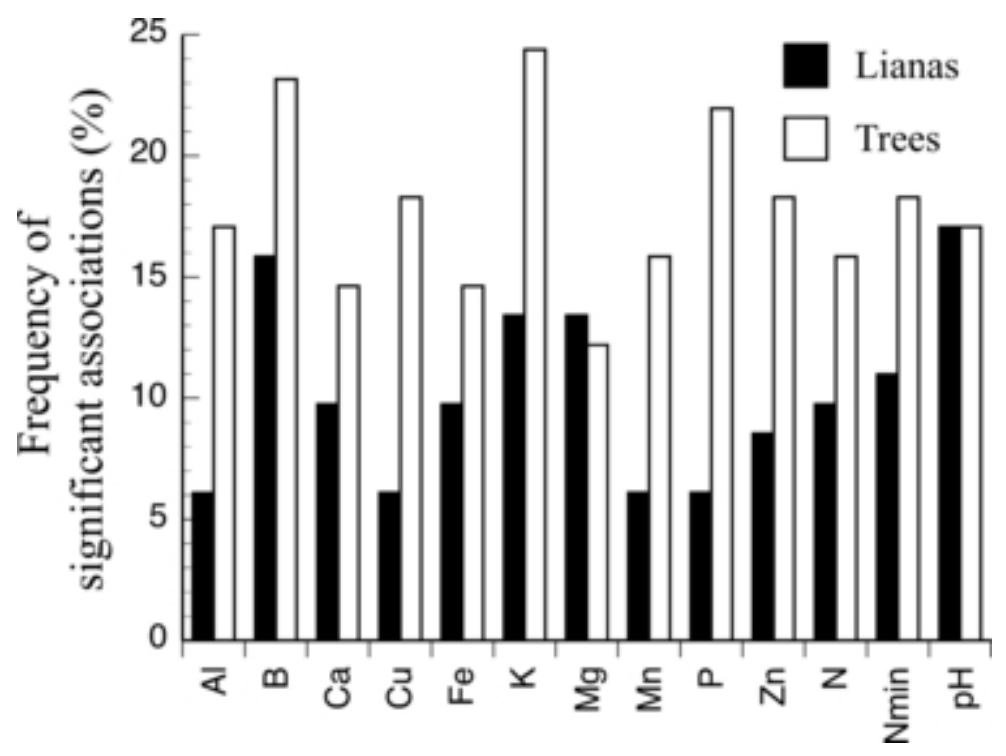

Figure 3

Percentage frequency of significant associations $(P<0.05)$ between liana species (filled bars) and tree species (open bars) with individual soil variables. Associations can be either positive (species occur in quadrats with higher than expected values of the variable) or negative (lower than expected). Analysis is restricted to the 82 liana species with $>65$ individuals, and a sample of 82 tree species with similar population sizes.

\section{Association of Lianas with Light Gaps}

For all species combined, we found that the density of liana individuals was significantly associated with low canopy heights (Table S3). Canopy height and the fraction of the forest canopy under gaps were almost identical for the high and low plateau habitats (Table 1). However, the slope habitat had smaller gap fraction, which may in part explain its relatively low liana density. A large fraction of liana species (63\%) were significantly associated with lower canopy heights than the random expectation (Table S3). Few of these associations are likely to be spurious as, on average, only $5 \%$ of species showed significant associations when species distributions were tested against the canopy height data from neighbouring 50-ha forest patches. Species associated with a low 
canopy did not differ from those that were not associated with a low canopy in their frequency of association with either topographic habitat types (Fisher exact test, $P=0.57$ ) or PC axes derived from soil chemical variables (Fisher exact test, $P=0.83$ ).

\section{Discussion}

\section{Variation in Liana Density Across the $\mathrm{BCl}$ 50-ha Forest Dynamics Plot}

Overall, the density of liana individuals was significantly higher on the commonest habitat type - the low plateau (Table 1). The higher liana density on the plateau, which maintains lower dry season soil water potential than slopes (Becker et al. 1988; Daws et al. 2002), may reflect a higher competitive ability of lianas in drier, more seasonal environments (Schnitzer 2005). A preference for drier, more seasonal forest has been attributed to deeper rooting systems (Tyree \& Ewers 1996; Andrade et al. 2005), and more efficient vascular systems in lianas than trees (Holbrook, Whitbeck \& Mooney 1995), which allows lianas to remain photosynthetically active when many trees are physiologically dormant ( $\underline{\text { Schnitzer 2005)}}$.

Regional scale studies have shown that the density and basal area of lianas is negatively correlated with annual

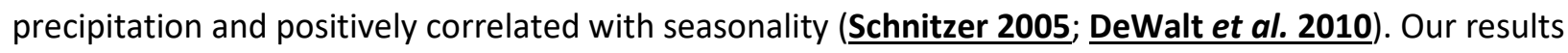
therefore suggest that regional habitat preferences may also be manifested at local scales. This is consistent with a study by Engelbrecht et al.(2007), which compared the regional distribution of tree species along a rainfall gradient across the Isthmus Panama, with the local distribution of the same species across the $\mathrm{BCl} 50$-ha plot. They found that the species that occurred on the drier side of the Isthmus were locally more abundant on the plateau habitat within the $\mathrm{BCl}$ plot. Thus, lianas, like drought-adapted trees, may compete best on drier soils. Liana densities were lowest on the wetter slope habitat, a result that contrasts with tree above-ground biomass on $\mathrm{BCl}$. Lidar measurements on $\mathrm{BCl}$ show that canopy heights (Table 1), and corresponding biomass estimates are greatest on slopes (Mascaro et al. 2010).

The relatively low liana density on slopes however may also reflect variation in the gap disturbance regime across the plot; the area of the slope habitat under gaps was $25 \%$ lower than the plateau habitats (Table 1 ). Nonetheless, liana densities were similar between the high plateau and slope, while the swamp, which had the highest gap area apart from streamsides, also had the lowest liana density.

Contrary to expectation, liana densities were not significantly higher in secondary than old-growth forest. Several studies report that liana abundance is higher in young secondary forests than in older forests (DeWalt, Schnitzer \& Denslow 2000; Letcher \& Chazdon 2009). In the forests around BCl, however, liana abundance peaks in fairly young seasonal forests ( $<70$ years old), while liana abundance does not differ in older age classes of forest (DeWalt, Schnitzer \& Denslow 2000). The failure to detect an association between liana density and forest age in this study may therefore either reflect the advanced age of the secondary forest in the $\mathrm{BCl}$ plot ( $>100$ years; Foster \& Brokaw 1982), where mean canopy height is $>20 \quad \mathrm{~m}$, or the relatively small spatial extent of this habitat type $(<2$ ha).

\section{Liana Associations with Habitat and Soil Variables}

Liana species were less frequently associated with individual habitat variables than were tree species. Whereas $66 \%$ of tree species showed associations with one or more topographically defined habitat types (Harms et al. 2001), 44\% of lianas showed an association. Nonetheless, the distribution of significant associations across habitat types did not differ between the growth forms (ig. 2). In contrary to our prediction, we did not find a marked preference among liana species for the more seasonally dry plateau habitat types, despite the significantly higher liana density, and spatial extent, of the lower plateau. Thus, few species appear to be restricted in their local distribution by virtue of a higher competitive advantage in drier sites, while 
perhaps some lianas, like trees, are relatively drought sensitive and are restricted to moister slope and swamp habitats.

Liana species were also less frequently associated with soil chemical variables than trees. Whereas $52 \%$ of tree species were associated with at least one of the three principal component axes of the soil variables, only $21 \%$ liana species showed an association. Using the most conservative test, where a null model is used to estimate the frequency of spurious associations, we found that only $6 \%$ of liana species were significantly associated with soil variables, compared with an overall association rate of $18 \%$ for the matched sample of tree species.

The low frequency of association of lianas with soil variables comes despite the expectation that lianas are more nutrient demanding than most trees, with potentially stronger selective effects of soil fertility on species distribution. Lianas tend to have higher foliar nutrient concentration, lower specific leaf area and lower investment in structural and chemical defences than co-occurring tree species, regardless of soil type (Salzer, Matezki \& Kazda 2006; Asner \& Martin 2011). The low frequency of association found here contrasts with the results of DeWalt et al. (2006) who reported clear habitat associations for most (71\%) of the liana species surveyed in Sabah, Malaysia. The difference in habitat preference between these studies may be because DeWalt et al. examined three habitats with markedly different soil conditions (ranging from alluvial deposits to nutrient impoverished sandy soils), whereas we examine a single, continuous area where soil physical characteristics are more homogeneous (John et al. 2007).

\section{Liana Association with Low-Canopy Microsites}

The strong association of lianas with low-canopy sites in this study supports the hypothesis that disturbance drives patterns of liana distribution within forests (e.g. Putz 1984; Schnitzer, Dalling \& Carson 2000; Schnitzer \&

Carson 2001; Foster, Townsend \& Zganjar 2008). The majority (63\%) of liana species were significantly positively associated with low canopy height microsites, indicative of areas recently disturbed by treefalls. Liana abundance, biomass and diversity are correlated with forest disturbance because lianas respond rapidly to increased light. Like trees, lianas vary in their capacity to tolerate low-light conditions in the forest understorey (Gilbert et al. 2006); however, lianas can respond to high light with exceptionally rapid growth - much faster than trees (e.g. Schnitzer, Parren \& Bongers 2004), providing a strong competitive advantage in gaps. Lianas can also recruit into gaps through the treefall process, where liana stems or stem fragments are brought down to the ground and subsequently proliferate (Putz 1984; Schnitzer, Dalling \& Carson 2000; Schnitzer \& Carson 2001, 2010; S. R. Yorke, unpublished data). The strong association of lianas with treefall gaps, together with the rarity of liana associations with soil variables, indicates that liana distributions within the forest may be primarily driven by canopy disturbance, either directly or possibly via interactions between topography and canopy disturbance, rather than by their sensitivity to soil chemical factors.

Once canopy gaps form, liana populations can be remarkably persistent. Schnitzer, Dalling \& Carson (2000) estimated that $7.5 \%$ of canopy gaps that form annually in the $\mathrm{BCl}$ plot become dominated by lianas, suppressing the regeneration of shade-tolerant tree species and stalling a recovery to high canopy forest. Much of the spatial aggregation of liana populations may therefore reflect the disturbance history of the plot integrated over a decade or longer time-scale.

\section{Implications of Liana Habitat Associations under Global Change}

Recent evidence indicates that liana abundance, biomass and productivity are increasing in neotropical forests (Schnitzer \& Bongers 2011). On BCl, liana leaf litter production rose by 55\% between 1986 and 2002 (Wright et al. 2004). Our results, along with previous studies (Putz 1984; Schnitzer, Dalling \& Carson 2000; Schnitzer \& Carson 2001; Foster, Townsend \& Zganjar 2008), indicate that increasing liana abundance and biomass might be explained by increased levels of disturbance (Schnitzer \& Bongers 2011). Increased 
disturbance, in turn, may be a consequence of stimulated productivity and tree turnover because of elevated atmospheric $\mathrm{CO}_{2}$ or irradiance (Phillips et al. 1998, 2004; Weishampel, Godin \& Henebry

2001; Lewis et al. 2004). Alternatively, increased liana abundance may reflect increases in the strength and frequency of seasonal droughts (Schnitzer \& Bongers 2011), which increase tree mortality (Condit, Hubbell \& Foster 1995; Nakagawa et al. 2000; Phillips et al. 2009). As liana abundance and biomass peak in seasonal forests, and in drier habitat patches within a forest, increasing frequency and severity of drought will likely favour lianas, with a concomitant reduction in above-ground biomass storage (van der Heijden \& Phillips 2009).

Nutrient deposition, particularly nitrogen from industrial pollution, is also increasing in tropical forests and has been hypothesized to contribute to liana increases (Schnitzer \& Bongers 2011). Liana leaves tend to have higher nitrogen content than those of their host trees (Salzer, Matezki \& Kazda 2006; Asner \& Martin 2011), which suggests lianas will respond more strongly to $\mathrm{N}$ fertilization (Schnitzer \& Bongers 2011). However, the lack of strong affinity of lianas to soil variables found in this study, compared to the much stronger correlation between trees and soil variables found in this and other forests (Clark, Palmer \& Clark

1999; Russo et al. 2005; John et al. 2007), suggests that lianas may not respond as strongly as predicted to increased nutrient deposition. In summary, liana abundance and distribution within the $\mathrm{BCl}$ forest appears to be driven mostly by disturbance and soil moisture, with a more limited role for soil nutrients.

\section{Acknowledgements}

We gratefully acknowledge financial and logistic support from the Smithsonian Tropical Research Institute and the National Science Foundation for grants DEB021104, 021115, 0212284 and 0212818 supporting soils mapping in the BCI plot, DEB0939907 for LiDAR data collection and DEB0613666 for the liana census. We thank Alicia Ledo for assistance with preparing Fig. 1. Additional support was provided to EL and CB from the Program in Ecology and Evolutionary Biology, University of Illinois.

\section{References}

Andrade, J.L., Meinzer, F.C., Goldstein, G. \& Schnitzer, S.A. (2005) Water uptake and transport in lianas and cooccurring trees of a seasonally dry tropical forest. Trees, 19, 282- 289.

Arroyo-Rodríguez, V. \& Toledo-Aceves, T. (2009) Impact of landscape spatial pattern on liana communities in tropical rainforests at Los Tuxtlas, Mexico. Applied Vegetation Science, 12, 340- 349.

Asner, G.P. \& Martin, R.E. (2011) Canopy phylogenetic, chemical and spectral assembly in a lowland Amazonian forest. New Phytologist, 189, 999- 1012.

Baddeley, A. \& Turner, R. (2005) Spastat: an R package for analyzing spatial point patterns. Journal of Statistical Software, 12, 1- 42.

Becker, P., Rabenold, P.E., Idol, J.R. \& Smith, A.P. (1988) Water potential gradients for gaps and slopes in a Panamanian tropical moist forest's dry season. Journal of Tropical Ecology, 4, 173- 184.

Burnham, R.J. (2002) Dominance, diversity and distribution of lianas in Yasuní, Ecuador: who is on top? Journal of Tropical Ecology, 18, 845-864.

Burnham, R.J. (2004) Alpha and beta diversity of Lianas in Yasuní National Park, Ecuador. Forest Ecology and Management, 190, 43- 55.

Campbell, E.J.F. \& Newbery, D.M. (1993) Ecological relationships between lianas and trees in lowland rain-forest in Sabah, East Malaysia. Journal of Tropical Ecology, 9, 469- 490.

Chettri, A., Barik, S.K., Pandey, H.N. \& Lyngdoh, M.K. (2010) Liana diversity and abundance as related to microenvironment in three forest types located in different elevational ranges of the Eastern Himalayas. Plant Ecology and Diversity, 3, 175- 185.

Clark, D.B., Palmer, M.W. \& Clark, D.A. (1999) Edaphic factors and the landscape scale distributions of tropical rainforest trees. Ecology, 80, 2662- 2675. 
Condit, R., Hubbell, S.P. \& Foster, R.B. (1995) Mortality rates of 205 neotropical tree and shrub species and the impact of a severe drought. Ecological Monographs, 65, 419-439.

Condit, R., Ashton, P.S., Baker, P., Buyavejchewin, S., Gunatilleke, S., Gunatilleke, N. et al. (2000) Spatial patterns in the distribution of tropical tree species. Science, 288, 1414- 1418.

Croat, T.B. (1978) Flora of Barro Colorado Island. Stanford University Press, Stanford, CA.

Daws, M.I., Mullins, C.E., Burslem, D.F.R.P., Paton, S.R. \& Dalling, J.W. (2002) Topographic position affects the water regime in a semi-deciduous tropical forest in Panama. Plant and Soil, 238, 79- 90.

DeWalt, S.J., Schnitzer, S.A. \& Denslow, J.S. (2000) Density and diversity of lianas along a seasonal tropical forest chronosequence in central Panama. Journal of Tropical Ecology, 16, 1- 19.

DeWalt, S.J., Ickes, K., Nilus, R., Harms, K.E. \& Burslem, D.F.R.P. (2006) Liana habitat associations and community structure in a Bornean lowland tropical forest. Plant Ecology, 186, 203- 216.

DeWalt, S.J., Schnitzer, S.A., Chave, J., Bongers, F., Burnham, R.J., Cai, Z.Q. et al. (2010) Annual rainfall and seasonality predict pan-tropical patterns of liana density and basal area. Biotropica, 42, 309- 317.

Engelbrecht, B.M.J., Comita, L.S., Condit, R., Kursar, T.A., Tyree, M.T., Turner, B.L. \& Hubbell, S.P. (2007) Drought sensitivity shapes species distribution patterns in tropical forests. Nature, 447, 80-82.

Foster, R.B. \& Brokaw, N.V.L. (1982) Structure and history of the vegetation of Barro Colorado Isalnd. The Ecology of a Tropical Forest (eds A. Rand \& E. Leigh), pp. 67-81. Smithsonian Institution Press, Washington, DC.

Foster, J.R., Townsend, P.A. \& Zganjar, C.E. (2008) Spatial and temporal patterns of gap dominance by lowcanopy lianas detected using EO-1 Hyperion and Landsat Thematic Mapper. Remote Sensing of Environment, 112, 2104- 2117.

Gentry, A.H. (1991) The distribution and evolution of climbing plants. The Biology of Vines (eds F.E. Putz \& H.A. Mooney), pp. 3- 49. Cambridge University Press, Cambridge.

Gerwing, J.J., Schnitzer, S.A., Burnham, R.J., Bongers, F., Chave, J., DeWalt, S.J. et al. (2006) A standard protocol for liana censuses. Biotropica, 38, 256- 261.

Gilbert, B., Wright, S.J., Muller-Landau, H.C., Kitajima, K. \& Hernandez, A. (2006) Life history trade-offs in tropical trees and lianas. Ecology, 87, 1281- 1288.

Gunatilleke, C.V.S., Gunatilleke, I.A.U.N., Esufali, S., Harms, K.E., Ashton, P.M.S., Burslem, D.F.R.P. \& Ashton, P.S. (2006) Species-habitat associations in a Sri Lankan dipterocarp forest. Journal of Tropical Ecology, 22, 371- 384.

Harms, K.E., Condit, R., Hubbell, S.P. \& Foster, R.B. (2001) Habitat associations of trees and shrubs in a 50-ha neotropical forest plot. Journal of Ecology, 89, 947- 959.

Hegarty, E.E. (1991) Vine-host interactions. The Biology of Vines (eds F.E. Putz \& H.A. Mooney), pp. 313- 335. Cambridge University Press, Cambridge.

van der Heijden, G.M.F. \& Phillips, O.L. (2009) Liana infestation impacts tree growth in a lowland tropical moist forest. Biogeosciences, 6, 2217- 2226.

Holbrook, N.M., Whitbeck, J.L. \& Mooney, H.A. (1995) Drought responses of Neotropical dry forest trees. Seasonally Dry Tropical Forests (eds S.H. Bullock, H.A. Mooney \& E. Medina), pp. 243- 276. Cambridge University Press, Cambridge.

Hubbell, S.P. \& Foster, R.B. (1983) Diversity of canopy trees in a neotropical forest and implications for conservation. Tropical Rain Forest: Ecology and Management (eds S. Sutton, T. Whitmore \& A. Chadwick), pp. 25-41. Blackwell Science, Oxford.

Ingwell, L.L., Wright, S.J., Becklund, K.K., Hubbell, S.P. \& Schnitzer, S.A. (2010) The impact of lianas on 10 years of tree growth and mortality on Barro Colorado Island, Panama. Journal of Ecology, 98, 879- 887.

John, R., Dalling, J.W., Harms, K.E., Yavitt, J.B., Stallard, R.F., Mirabello, M., Hubbell, S.P., Valencia, R., Navarrete, H., Vallejo, M. \& Foster, R.B. (2007) Soil nutrients influence spatial distributions of tropical tree 
species. Proceedings of the National Academy of Sciences of the United States of America, 104, 864-869.

Johnson, M.J. \& Stallard, R.F. (1989) Physiographic controls on the composition of sediments derived from volcanic and sedimentary terrains on Barro Colorado Island, Panama. Journal of Sedimentary Petrology, 59, 768- 781.

Laurance, W.F., Perez-Salicrup, D., Delamonica, P., Fearnside, P.M., D’Angelo, S., Jerozolinski, A., Pohl, L. \& Lovejoy, T.E. (2001) Rain forest fragmentation and the structure of Amazonian liana communities. Ecology, 82, 105- 116.

Letcher, S.G. \& Chazdon, R.L. (2009) Lianas and self-supporting plants during tropical forest succession. Forest Ecology and Management, 257, 2150- 2156.

Lewis, S.L., Phillips, O.L., Baker, T.R., Lloyd, J., Malhi, Y., Almeida, S. et al. (2004) Concerted changes in tropical forest structure and dynamics: evidence from 50 South American long-term plots. Philosophical Transactions of the Royal Society of London Series B, 359, 421- 436.

Malizia, A., Grau, H.R. \& Lichstein, J.W. (2010) Soil phosphorus and disturbance influence liana communities in a subtropical montane forest. Journal of Vegetation Science, 21, 551- 560.

Mascaro, J., Asner, G.P., Muller-Landau, H.C., van Breugel, M., Hall, J. \& Dahlin, K. (2010) Controls over aboveground forest carbon density on Barro Colorado Island, Panama Biogeosciences. Discussions, 7, 8817-8852.

Nakagawa, M., Tanaka, K., Nakashizuka, T., Ohkubo, T., Kato, T., Maeda, T. et al. (2000) Impact of severe drought associated with the 1997-1998 El Niño in a tropical forest in Sarawak. Journal of Tropical Ecology, 16, 355- 367.

Parren, M.P.E., Bongers, F., Caballé, G., Nabe-Nielsen, J. \& Schnitzer, S.A. (2005) On censusing lianas: a review of the issues. Forest Climbing Plants of West Africa: Diversity, Ecology, and Management (eds F. Bongers, M.P.E. Parren \& D. Traore), pp. 41- 58. ABI Publishing, Wallingford.

Pebesma, E.J. (2004) Multivariable geostatistics in S: the gstat package. Computers and Geosciences, 30, 683-691.

Phillips, O.L., Malhi, Y., Higuchi, N., Laurance, W.F., Nunez, P.V., Vasquez, R.M., Laurance, S.G., Ferreira, L.V., Stern, M., Brown, S. \& Grace, J. (1998) Changes in the carbon balance of tropical forests: evidence from long-term plots. Science, 282, 439- 442.

Phillips, O.L., Vásquez, M.R., Arroyo, L., Baker, T., Killeen, T., Lewis, S.L. et al. (2002) Increasing dominance of large lianas in Amazonian forests. Nature, 418, 770- 774.

Phillips, O.L., Baker, T.R., Arroyo, L., Higuchi, N., Killeen, T.J., Laurance, W.F. et al. (2004) Pattern and process in Amazon tree turnover, 1976-2001. Philosophical Transactions of the Royal Society of London Series $B, 359,381-407$.

Phillips, O.L., Aragao, L.E.O.C., Lewis, S.L., Fisher, J.B., Lloyd, J., Lopez-Gonzalez, G. et al. (2009) Drought sensitivity of the Amazon rainforest. Science, 323, 1344- 1347.

Plotkin, J.B., Potts, M.D., Leslie, N., Manokoran, N., LaFrankie, J. \& Ashton, P.S. (2000) Species-area curves, spatial aggregation, and habitat specialization in tropical forests. Journal of Theoretical Biology, 207, 81- 99.

Potts, M.D., Davies, S.J., Bossert, W.H., Tan, S. \& Nur Supardi, M.N. (2004) Habitat heterogeneity and niche structure of trees in two tropical rain forests. Oecologia, 139, 446- 453.

Proctor, J., Anderson, J.M., Fogden, S.C.L. \& Vallack, H.W. (1983) Ecological studies in four contrasting lowland rain forests in Gunung Mulu National Park, Sarawak: I. Forest environment, structure and floristics. Journal of Ecology, 71, 237- 260.

Putz, F.E. (1984) The natural history of lianas on Barro Colorado Island, Panama. Ecology, 65, 1713- 1724.

Putz, F.E. \& Chai, P. (1987) Ecological studies on lianas in Lambir National Park, Sarawak, Malaysia. Journal of Ecology, 75, 523- 531. 
Putz, F.E. \& Mooney, H.A. (1991) The Biology of Vines. Cambridge University Press, Cambridge.

Ripley, B. (1976) The second-order analysis of stationary point processes. Journal of Applied Probability, 13, 255- 266.

Russo, S.E., Davies, S.J., King, D.A. \& Tan, S. (2005) Soil related performance variation and distributions of tree species in a Bornean rainforest. Journal of Ecology, 93, 879- 889.

Salzer, J., Matezki, S. \& Kazda, M. (2006) Nutritional differences, and leaf acclimation of climbing plants and the associated vegetation in different types of an Andean montane rainforest. Oecologia, 147, 417- 425.

Schnitzer, S.A. (2005) A mechanistic explanation for global patterns of liana abundance and distribution. American Naturalist, 166, 262- 276.

Schnitzer, S.A. \& Bongers, F. (2002) The ecology of lianas and their role in forests. Trends in Ecology and Evolution, 17, 223- 230.

Schnitzer, S.A. \& Bongers, F. (2011) Increasing liana abundance and biomass in tropical forests: emerging patterns and putative mechanisms. Ecology Letters, 14, 397- 406.

Schnitzer, S.A. \& Carson, W.P. (2001) Treefall gaps and the maintenance of species diversity in a tropical forest. Ecology, 82, 913-919.

Schnitzer, S.A. \& Carson, W.P. (2010) Lianas suppress tree regeneration and diversity in treefall gaps. Ecology Letters, 13, 849-857.

Schnitzer, S.A., Dalling, J.W. \& Carson, W.P. (2000) The impact of lianas on tree regeneration in tropical forest canopy gaps: evidence for an alternative pathway of gap-phase regeneration. Journal of Ecology, 88, 655- 666.

Schnitzer, S.A., DeWalt, S.J. \& Chave, J. (2006) Censusing and measuring lianas: a quantitative comparison of the common methods. Biotropica, 38, 581- 591.

Schnitzer, S.A., Parren, M.P.E. \& Bongers, F. (2004) Recruitment of lianas into logging gaps and the effects of preharvest climber cutting in a lowland forest in Cameroon. Forest Ecology and Management, 190, 87- 98.

Schnitzer, S.A., Rutishauser, S. \& Aguilar, S. (2008) Supplemental protocol for liana censuses. Forest Ecology and Management, 255, 1044- 1049.

Tyree, M. \& Ewers, F.W. (1996) Hydraulic architecture of woody tropical plants. Tropical Forest Plant Ecophysiology (eds S. Mulkey, R.L. Chazdon \& A.P. Smith), pp. 217- 243. Chapman \& Hall, New York.

Valencia, R., Foster, R.B., Muñoz, G.V., Condit, R., Svenning, J.-C., Hernandez, C., Romoleroux, K., Losos, E., Magard, E. \& Balslev, H. (2004) Tree species distributions and local habitat variation in the Amazon: large forest plot in eastern Ecuador. Journal of Ecology, 92, 214- 229.

Weishampel, J.F., Godin, J.R. \& Henebry, G.M. (2001) Pantropical dynamics of 'intact' rain forest canopy texture. Global Ecology and Biogeography, 10, 389- 397.

Windsor, D.M. (1990) Climate and moisture variability in a tropical forest: long-term records from Barro Colorado Island, Panamá. Smithsonian Contributions to the Earth Sciences, 29, 1- 145.

Wright, S.J., Calderon, O., Hernandéz, A. \& Paton, S. (2004) Are lianas increasing in importance in tropical forests? A 17 year record from Panama Ecology, 85, 484- 489. 